\title{
Media Pembelajaran Bahasa Mee Tingkat Dasar Berbasis Multimedia Interaktif

\author{
${ }^{1}$ Mayor M.H. Manurung , ${ }^{2}$ Ankian Bunai, ${ }^{3}$ Halomoan Edy Manurung \\ ${ }^{1}$ Universitas Cenderawasih, Indonesia \\ ${ }^{2,3}$ Universitas Ottow Geissler Papua, Indonesia

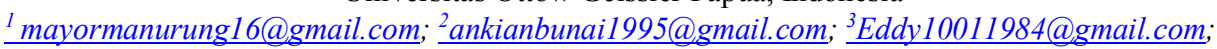

\begin{tabular}{l}
\hline \hline Article Info \\
\hline Article history: \\
Received, 02-01-2021 \\
Revised, 15-01-2021 \\
Accepted, 29-01-2021 \\
\\
\hline Kata Kunci: \\
Media Pembelajaran \\
Multimedia interaktif \\
Macromedia Flash \\
Aplikasi Audio Lexis \\
Bahasa Mee
\end{tabular}

Keywords:

Learning Media

Interactive Multimedia

Macromedia Flash

Lexis Audio Application

Mee Language

\begin{abstract}
ABSTRAK
Hampir seluruh pekerjaan manusia dapat diselesaikan oleh komputer baik dalam hal yang berkenaan dengan pengolahan data, pengolahan kata, pengolahan metode, pengolahan gambar dan lain sebagainya sehingga dapat dikatakan bahwa suatu informasi akan menjadi lebih efektif dan efisien dengan menerapkan komputerisasi. Salah satu bidang yang terdampak dengan perkembangan teknologi komputer adalah di bidang pendidikan. Peran Teknologi komputer dibidang pendidikan salah satunya adalah penggunaan media pembelajaran pada proses belajar mengajar. Papua memiliki sekitar 240 bahasa dan beragam budaya sehingga perlu adanya upaya pelestarian budaya dan bahasa daerah dari usia dini. Bahasa Mee yang adalah salah satu bahasa daerah dari Papua tepatnya di Kabupaten Paniai perlu dilestarikan dari segi bahasa dan sistem bilangan dengan menggunakan suatu media pembelajaran interaktif agar tidak terjadi kepunahan dari segi bahasa dan kebudayaannya dimasa mendatang. Oleh karena itu peneliti telah mengembangkan suatu media pembelajaran bahasa Mee pada tingkat dasar berbasis multimedia interaktif dengan menggunakan Macromedia Flash CS8 dan Aplikasi Audio lexis guna pelestarian bahasa dan kebudayaan khususnya di Papua. Media Pembelajaran yang dibangun terdiri dari Angka, Kata Kerja, Kata Benda, Hubungan Kekerabatan, kata sifat, kata ganti, kalimat serta soal atau kuis yang menyangkut Bahasa mee secara interaktif yang terdiri dari animasi, gambar, audio. Hasil yang diperoleh dari hasil validasi ahli media adalah $85 \%$ dan ahli materi adalah $90 \%$ sehingga dapat dikategorikan sangat baik maka dapat disimpulkan bahwa media pembelajaran bahasa Mee pada tingkat dasar berbasis multimedia interaktif layak digunakan.
\end{abstract}

\section{ABSTRACT}

Almost all human work can be completed by computers equally in terms of data processing, word processing, processing methods, image processing, and others. So that it can be said that information will become more effective and efficient by applying computerization. One of the areas affected by the development of computer technology is in the field of education. The role of computer technology in the field of education is one of them is the use of learning media in the teaching and learning process. Papua has about 240 languages in addition diverse cultures accordingly there need to be efforts to preserve local culture and language from an early age. Mee language which is one of the regional languages from Papua precisely in Paniai Regency needs to be preserved in terms of language and number system by using an interactive learning media so that there is no extinction in terms of language and culture in the future. Therefore, researchers have developed a mee language learning media at the basic level based on interactive multimedia using Macromedia Flash CS8 and Audio Lexis Application for the preservation of language and culture, especially in Papua. Learning Media built consists of Numbers, Verbs, Nouns, Kinship Relationships, adjectives, pronouns, sentences, and questions or quizzes related to Mee language interactively consisting of 
animations, images, audio. The results obtained from the validation results of media experts are $85 \%$ and the material expert is $90 \%$ so that it can be categorized very well then it can be generalized that Mee language learning media at the basic level based on interactive multimedia is worth using.

\author{
Penulis Korespondensi: \\ Halomoan Edy Manurung, \\ Program Studi sistem informasi, \\ Universitas Ottow Geissler Papua, \\ Email: Eddy10011984@gmail.com
}

\title{
a. PENDAHULUAN
}

Perkembangan teknologi informasi saat ini begitu pesat seperti di bidang komputer baik yang bersifat perangkat keras (hardware) maupun perangkat lunak (software) yang memudahkan hampir seluruh pekerjaan manusia. Sehingga komputer dapat memaksimalkan dan mengefisienkan suatu pekerjaan yang dilakukan manusia baik dalam hal pengolahan kata, pengolahan gambar, pengolahan suara maupun pemprosesan data dan lain sebagainya. Salah satu alasan, mengapa komputer cenderung digunakan sebagai alat bantu dalam menyelesaikan suatu pekerjaan karena pekerjaan yang dilakukan menggunakan komputer memiliki kecepatan proses yang lebih dapat diandalkan.

Dengan berkembangnya revolusi industry 4.0 maka hampir semua pekerjaan dilakukan secara komputerisasi. Salah satu aspek yang mengalami dampak akibat perubahan tersebut yaitu pada bidang Pendidikan dimana proses belajar mengajar yang dilakukan saat ini menggunakan teknologi komputer seperti materi ajar yang dibuat dan dipresentasikan, pertemuan secara online meggunakan software-software pendukung, ujian online dan lain sebagainya. Kegiatan proses belajar mengajar yang dapat dipakai untuk membuat pembelajaran antara lain media pembelajaran. Dalam hal ini peneliti ingin membuat suatu pembelajaran secara interaktif dengan memakai teknologi komputer yang bertujuan untuk lebih mempermudah bagi siswa dalam proses belajar mengajar di kelas.

Adapun Model Pembelajaran yang dikembangkan adalah yang berhubungan dengan aspek kebudayaan dan bahasanya. Karena Bahasa adalah sebagai sistem komunikasi, memberikan mana dalam kebudayaan yang menjadi wadahnya sehingga Bahasa dan kebudayaan memiliki hubungan yang sangat erat.[1]

Ada beberapa penelitian yang membahas tentang aspek Bahasa dan budaya diantaranya adalah penelitian yang berjudul "Sistem Bilangan Tradisional Suku Ok dan Mek Di Pulau Papua", penelitian tersebut menggunakan lambang tubuh manusia berjumlah dua puluh tujuh (27) dari sistem bilangannya yang di mulai dari ibu jari kiri dan berakhir di jari kelingking kanan[2]. Penelitian berikutnya adalah "Perancangan Modul Pembelajaran Numeralia Dalam Bahasa Biak Berbasis interactive Multimedia Learning" [3], adapun yang dibahas adalah soal dan penjelasan tentang operasi hitung bilangan baik Penjumlahan, pengurangan, perkalian maupun pembagian. Sedangkan yang akan dirancang oleh peneliti adalah aplikasi Media pembelajaran Bahasa Mee Tingkat Dasar berbasis multimedia interaktif yang terdiri dari Angka, Kata Kerja, Kata Benda, Hubungan Kekerabatan, kata sifat, kata ganti, kalimat serta soal atau kuis yang menyangkut Bahasa mee. Dimana Bahasa Mee adalah salah satu Bahasa identitas Suku 
Mee yang terdapat di Papua, tepatnya di Kabupaten Paniai. Adapun beberapa Penelitian tentang media pembelajaran interaktif seperti penggunaanya dalam mata pelajaran bahasa Indonesia, bahasa inggris, kosa kata bahasa Arab, bahasa Jepang, bahasa isyarat anak tuna rungu, mata pelajaran matematika dan lain-lain [8][9][10][11][12][13][14][15][16].

Oleh karena latar belakang tersebut maka tujuan dari penelitian adalah membangun serta merancang "Media Pembelajaran Bahasa Mee Tingkat Dasar Berbasis Multimedia Interaktif", sehingga memberikan manfaat bagi pelestarian budaya dan Bahasa yang ada di Kabupaten Paniai Provinsi Papua.

\section{b. METODE PENELITIAN}

Metode penelian yang digunakan dalam penelitian ini adalah sebagai berkut:

\subsection{Kerangka Berpikir}

Berikut merupakan serangkaian bagan-bagan yang menggambarkan alur dari proses penelitian dalam pembuatan media pembelajaran bahasa mee tingkat dasar berbasis multimedia adalah sebagai berikut:

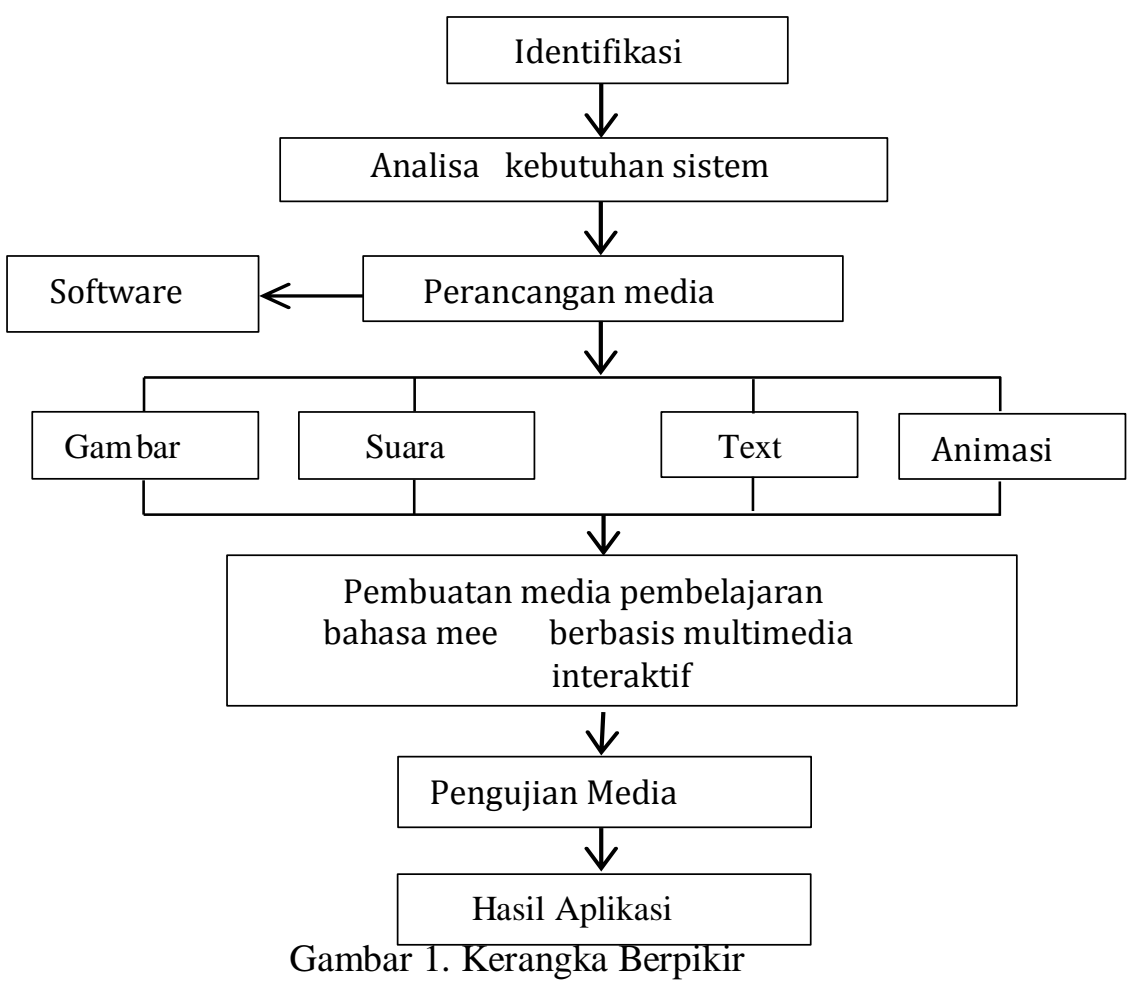

Berikut penjelasan dari gambar 1 tentang kerangka berpikir:

\section{a. Identifikasi masalah}

Pada tahapan ini penulis secara langsung mengidentifikasi masalah yang terjadi terkait dengan Media Pembelajaran Bahasa Mee Tingkat Dasar

b. Analisa sistem

Pada tahap ini penulis menganalisa sistem pembelajaran yang sedang berjalan di tingkat dasar pada Kabupaten Paniai atau sistem yang sudah ada dan menganalisa sistem usulan yang akan dibuat mulai dari menu intro aplikasi sampai menu-menu kalimat.

c. Perancangan sistem

Pada tahap ini dilakukan merancang sistem media pembelajaran bahasa mee tingkat dasar dengan perancangan diagram flowchart, perancangan storyboard dan 
perancangan antar muka pemakai yang akan dibuat berdasarkan hasil analisa yang telah dilakukan.

d. Pembuatan media

Pada tahap ini penulis akan membuat sistem aplikasi media pembelajaran yang sudah dirancang dengan menggunakan aplikasi dasar Adobe Dreamweaver CS8, Aplikasi lexis audio.

e. Pengujian Media

Tahap terakhir yang perlu dilakukan adalah menguji program yang sudah dibuat, apakah sudah siap di gunakan atau belum.

f. Hasil Aplikasi

Pada tahapan ini hasil terakhir dari aplikasi media pembejaran bahasa mee tingkat dasar berbasis multimedia interaktif yang telah di buat.[4]

2.2 Metode Pengambilan data

Untuk memperoleh data dan informasi yang dibutuhkan sehubungan dengan penulisan laporan tugas akhir ini, maka digunakan metode-metode sebagai berikut:

1. Metode observasi (studi lapangan)

Dalam metode ini dilakukan pengamatan langsung untuk mengetahui tentang sistem pembelajaran bahasa Mee di Kabupaten Paniai sebagai bahan objek penulisan untuk mengambil data-data yang diperlukan untuk bahan penelitian.

2. Metode interview (wawancara)

Dalam metode ini penulis dapat menanyakan kepada pihak-pihak yang bersangkutan secara langsung untuk mendapatkan data yang dibutuhkan agar dijadikan bahan penelitian

3. Studi pustaka

Metode pustaka untuk mendapat data dan informasi dengan membaca dan mempelajari buku-buku yang berhubungan dengan judul yang diangkat.[5]

\subsection{Metode Pengembangan sistem}

Metode pengembangan yang digunakan adalah metode Multimedia Development Life Cycle (MDLC) Versi Luther-Sutopo dalam Nanda adalah sebagai berikut:

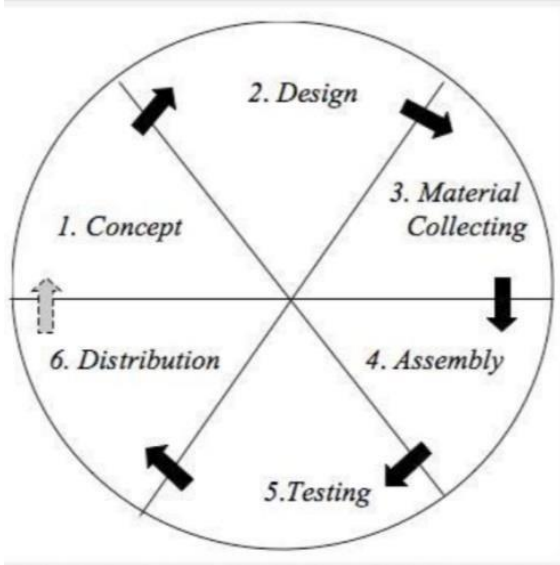

Gambar 2. Multimedia Development Life Cycle

Berikut penjelasan dari gambar 2.1 Tentang tahapan-tahapan siklus pengembangan sistem: 


\section{a. Konsep (Concept)}

Merumuskan dasar-dasar dari proyek multimedia yang akan dibuat dan dikembangkan.

Terutama pada tujuan dan jenis proyek yang akan dibuat

b. Desain/rancangan (Design)

Tahap dimana pembuat atau pengembang proyek multimedia menjabarkan secara rinci apa yang akan dilakukan dan bagaimana proyek multimedia tersebut akan dibuat. Pembuatan naskah atau navigasi serta proses desain lain harus secara lengkap dilakukan. Pada tahap ini penulis menggunakan perancangan struktur navigasi, perancangan flowchard, perancangan storyboard, dan perancangan antarmuka pemakai untuk mengetahui bagaimana hasil akhir dari poyek yang akan dikerjakan.

c. Pengumpulan materi (Optaining Content Material)

Merupakan proses untuk mengumpulkan segala sesuatu yang dibutuhkan dalam proyek mengenai materi yang akan disampaikan, kemudian file-file seperti audio, video dan gambar yang akan dimasukkan dalam penyajian proyek multimedia tersebut.

d. Penyusunan dan pembuatan (Assembly)

Waktunya proyek multimedia dibuat. Materi-materi serta file-file yang sudah didapat kemudian dirangkai dan disusun sesuai desain.

\section{e. Uji Coba (Testing)}

Setelah hasil dari proyek multimedia jadi, perlu dilakukan uji coba. Uji coba dilakukan dengan menerapkan hasil dari proyek multimedia tersebut pada pembelajaran secara minor. Hal ini dimaksud agar apa yang telah dibuat sebelumnya memang tepat sebelum dapat diterapkan dalam pembelajaran secara massal.

\section{f. Menyebar Luaskan (Distribution)}

Tahap penggandaan dan penyebaran hasil kepada pengguna. Multimedia perlu dikemas dengan baik sesuai dengan media penyebar luasnya, apakah melalui CD/DVD, download, ataupun media yang lain [6]. Salah satu bentuk distribusi sebuah media adalah dengan memanfaatkan media audio visual untuk menjadi daya tarik bagi masyarakat luas untuk menggunakannya [7].

\section{HASIL DAN ANALISIS}

Berikut ini menjelaskan hasil dari aplikasi media pembelajaran interaktif bahasa Mee

\subsection{Tampilan halaman intro}

Adapun halaman into dari aplikasi media pembelajaran interaktif bahasa mee terlihat gambar tiga (3) berikut ini;

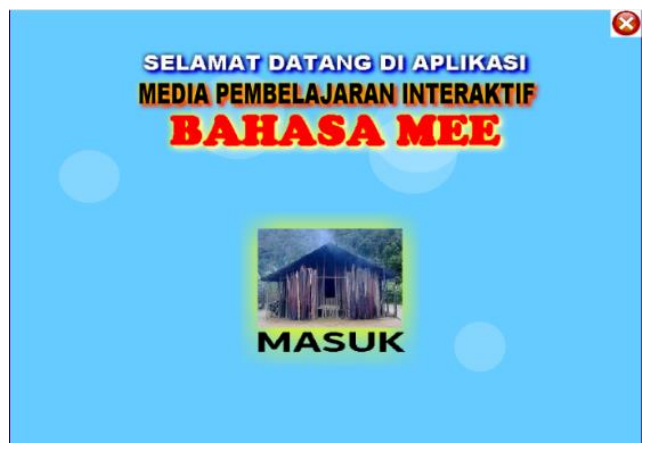

Gambar 3. Halaman intro 
JSAI : Journal Scientific and Applied Informatics

Vol. 4, No. 01, Januari 2021, hal. 64 74

E-ISSN: 2614-3054; P-ISSN: 2614-3062, accredited by Kemenristekdikti, Sinta 5

DOI: 10.36085

3.2 Halaman menu utama

Adapun halaman aplikasi media pembelajaran interaktif bahasa mee terlihat gambar 4.2 berikut ini.

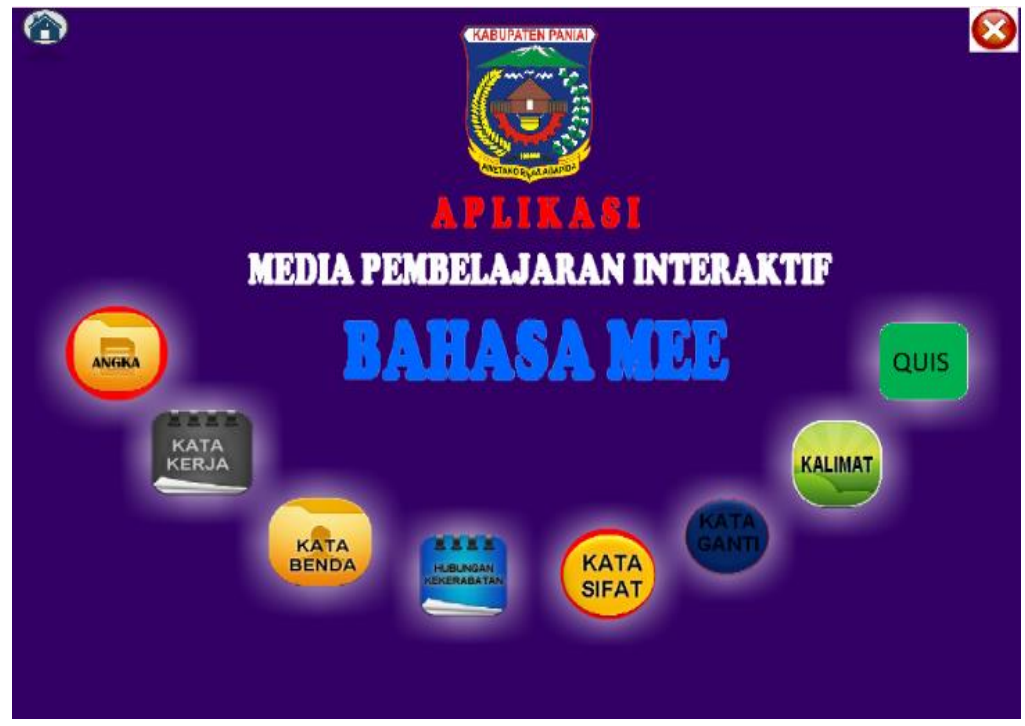

Gambar 4 Halaman Menu utama

3.3 Halaman menu angka

Adapun halaman menu angka aplikasi media pembelajaran interaktif bahasa mee terlihat gambar lima(5) berikut ini;

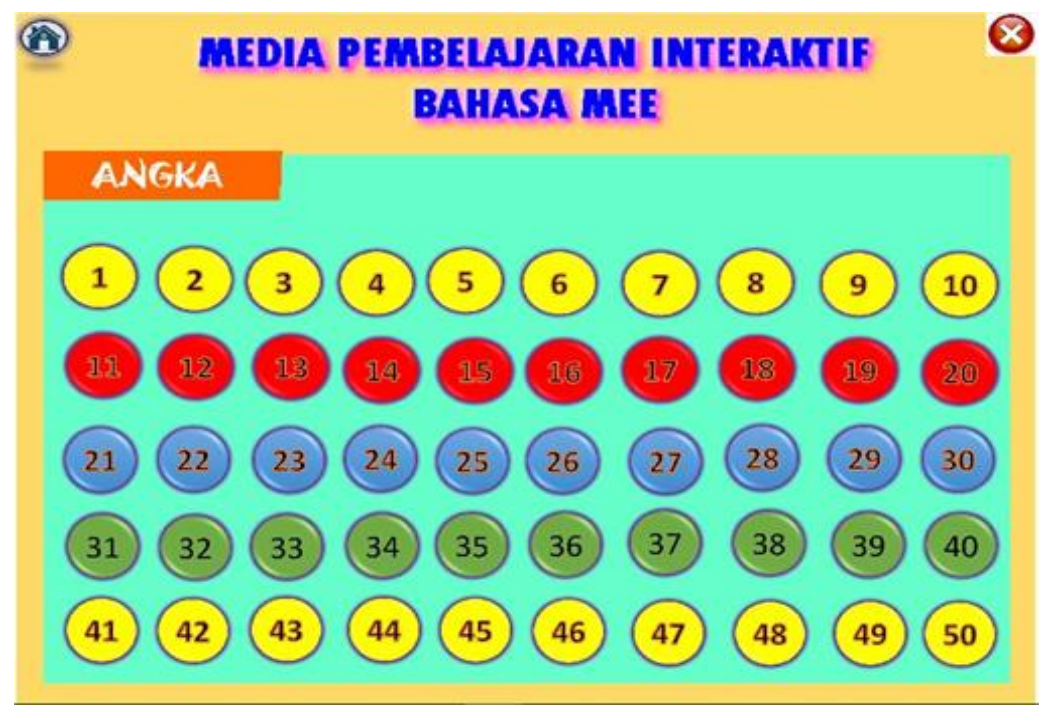

Gambar 5. Halaman angka

\subsection{Halaman kata kerja}

Adapun halaman menu kata kerja aplikasi media pembelajaran interaktif bahasa mee terlihat gambar enam (6) berikut ini; 


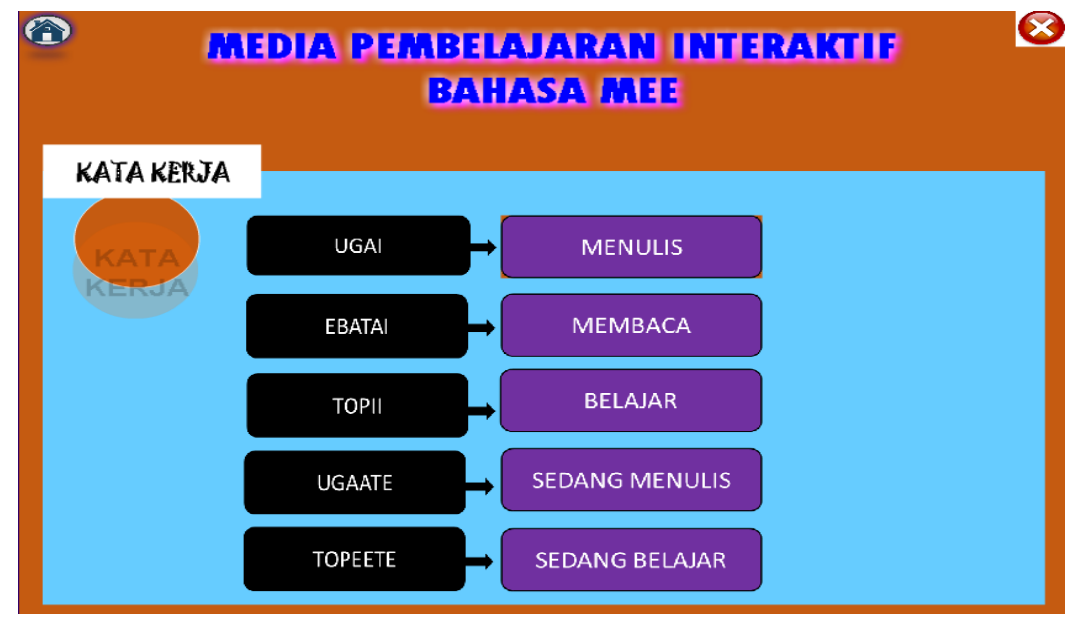

Gambar 6. Halaman Kata Kerja

3.5 Halaman kata benda

Adapun halaman menu kata benda aplikasi media pembelajaran interaktif bahasa mee terlihat gambar tujuh(7) berikut ini;

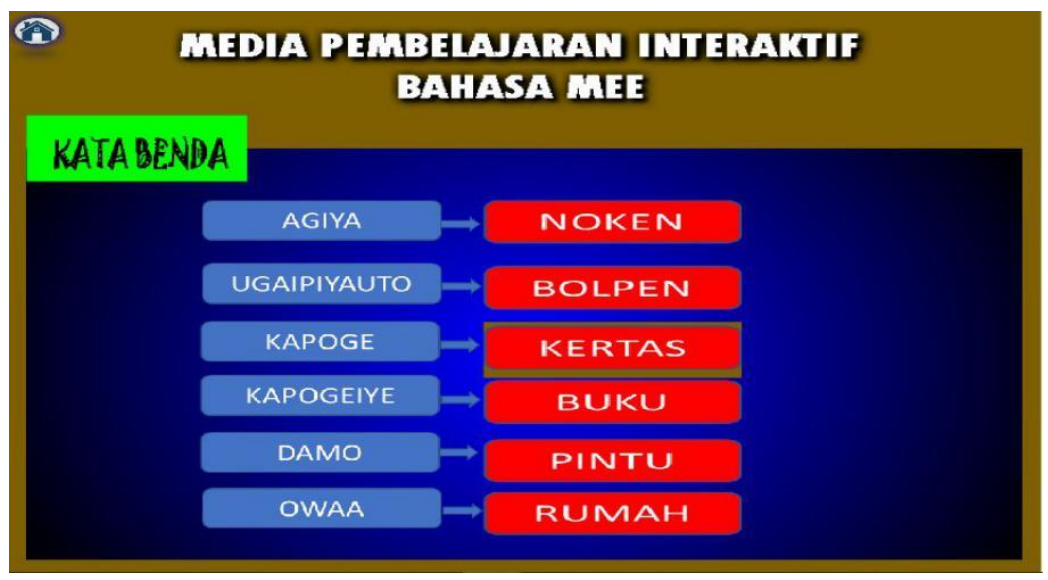

Gambar 7. Halaman kata Benda

3.6 Halaman hubungan kekerabatan

Adapun halaman menu hubungan kekerabatan aplikasi media pembelajaran interaktif bahasa mee terlihat gambar delapan (8) berikut ini; 
JSAI : Journal Scientific and Applied Informatics

Vol. 4, No. 01, Januari 2021, hal. 64 74

E-ISSN: 2614-3054; P-ISSN: 2614-3062, accredited by Kemenristekdikti, Sinta 5

DOI: 10.36085

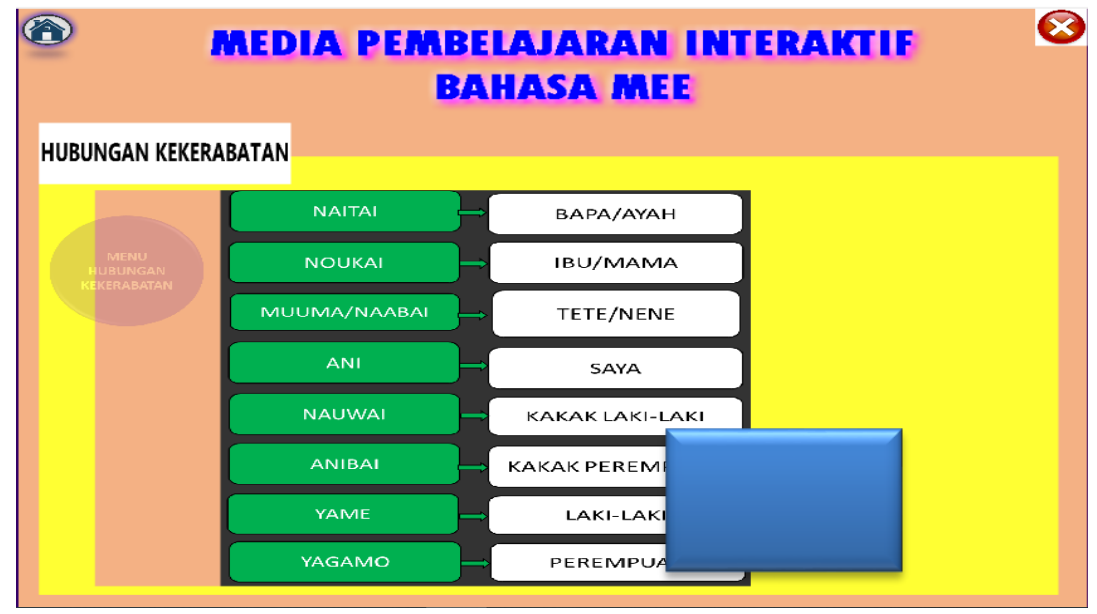

Gambar 8. Halaman hubungan kekerabatan

3.7 Menu kata sifat

Adapun halaman menu kata sifat aplikasi media pembelajaran interaktif bahasa mee terlihat gambar Sembilan (9) berikut ini;

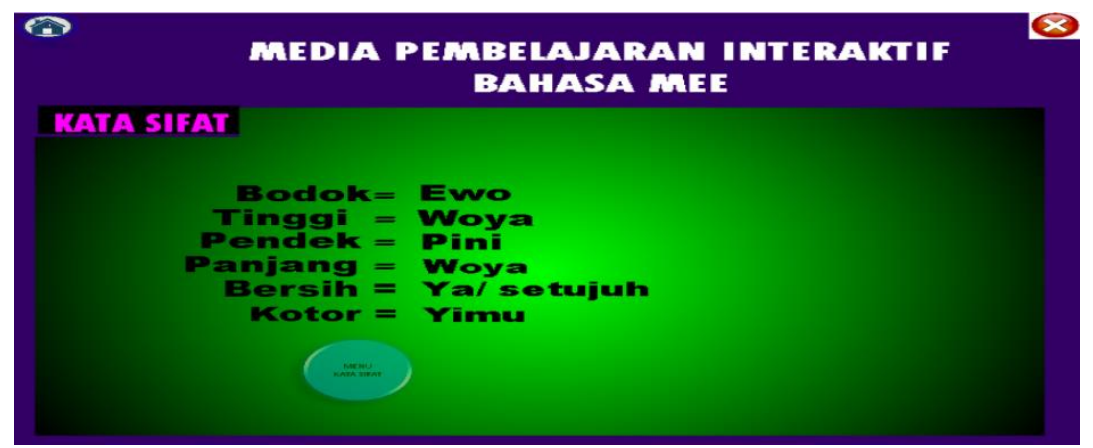

Gambar 9. Halaman kata sifat

3.8 Menu kata ganti

Adapun halaman menu kata ganti aplikasi media pembelajaran interaktif bahasa mee terlihat gambar sepuluh (10) berikut ini; 
JSAI : Journal Scientific and Applied Informatics

Vol. 4, No. 01, Januari 2021, hal. 64 74

E-ISSN: 2614-3054; P-ISSN: 2614-3062, accredited by Kemenristekdikti, Sinta 5

DOI: 10.36085

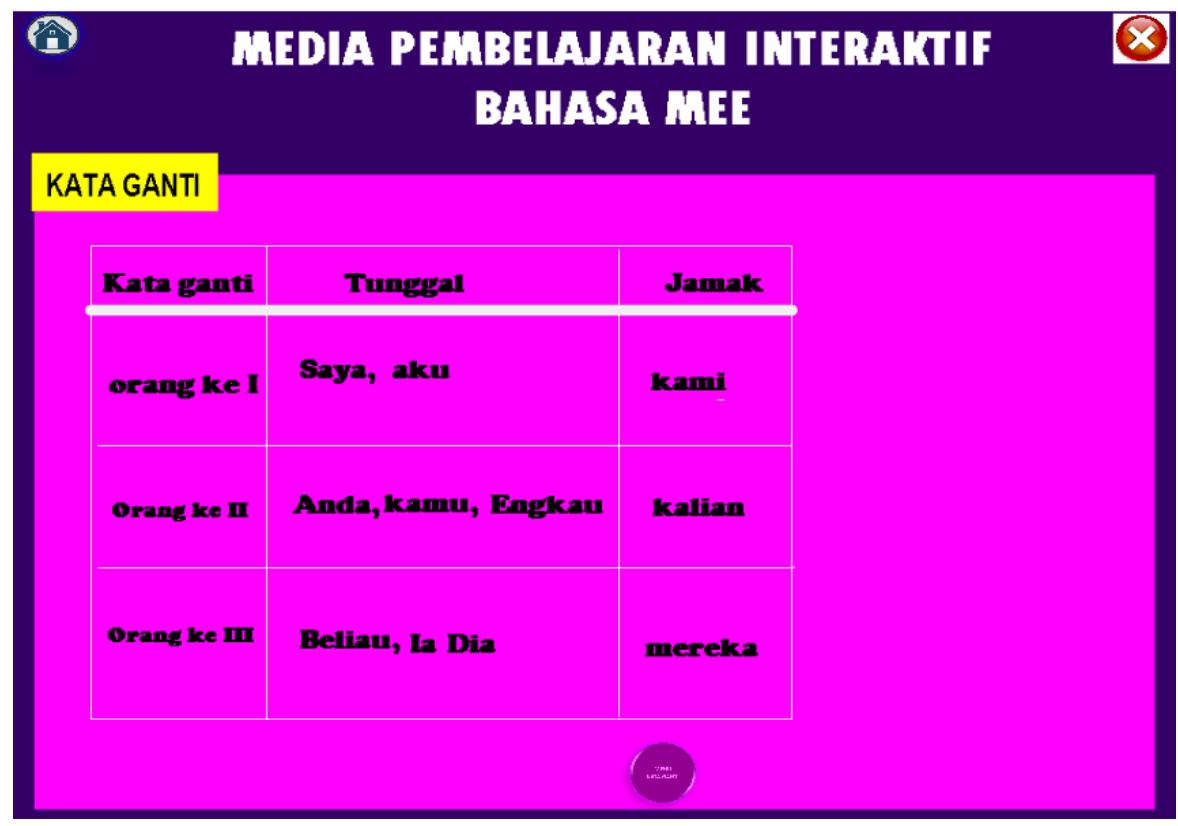

Gambar 10. Halaman kata ganti

3.9 Menu kalimat

Adapun halaman menu kata benda aplikasi media pembelajaran interaktif bahasa mee terlihat gambar sebelas (11) berikut ini;

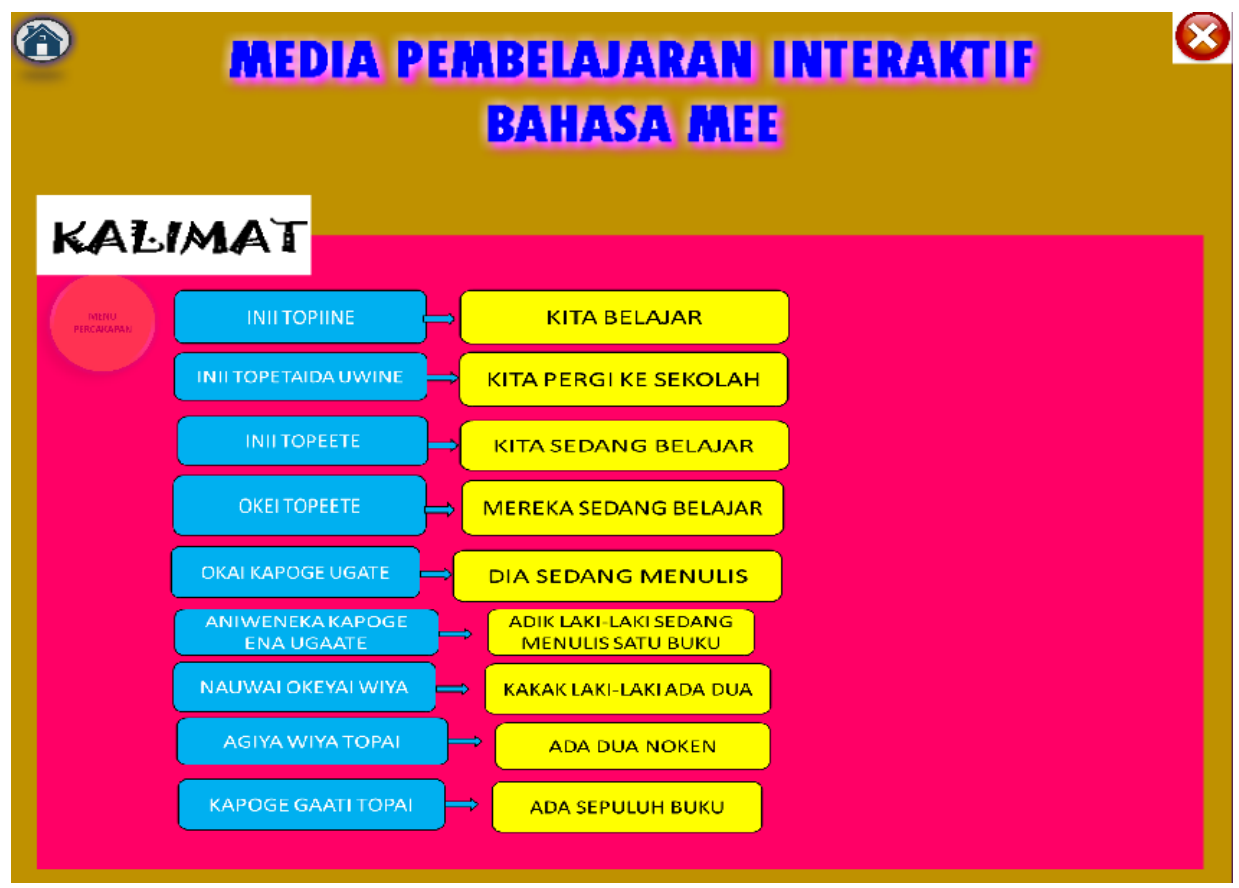

Gambar 11. Halaman kalimat

3.10 Menu Quis

Adapun halaman menu quis aplikasi media pembelajaran interaktif bahasa mee terlihat gambar dua belas (12) berikut ini; 


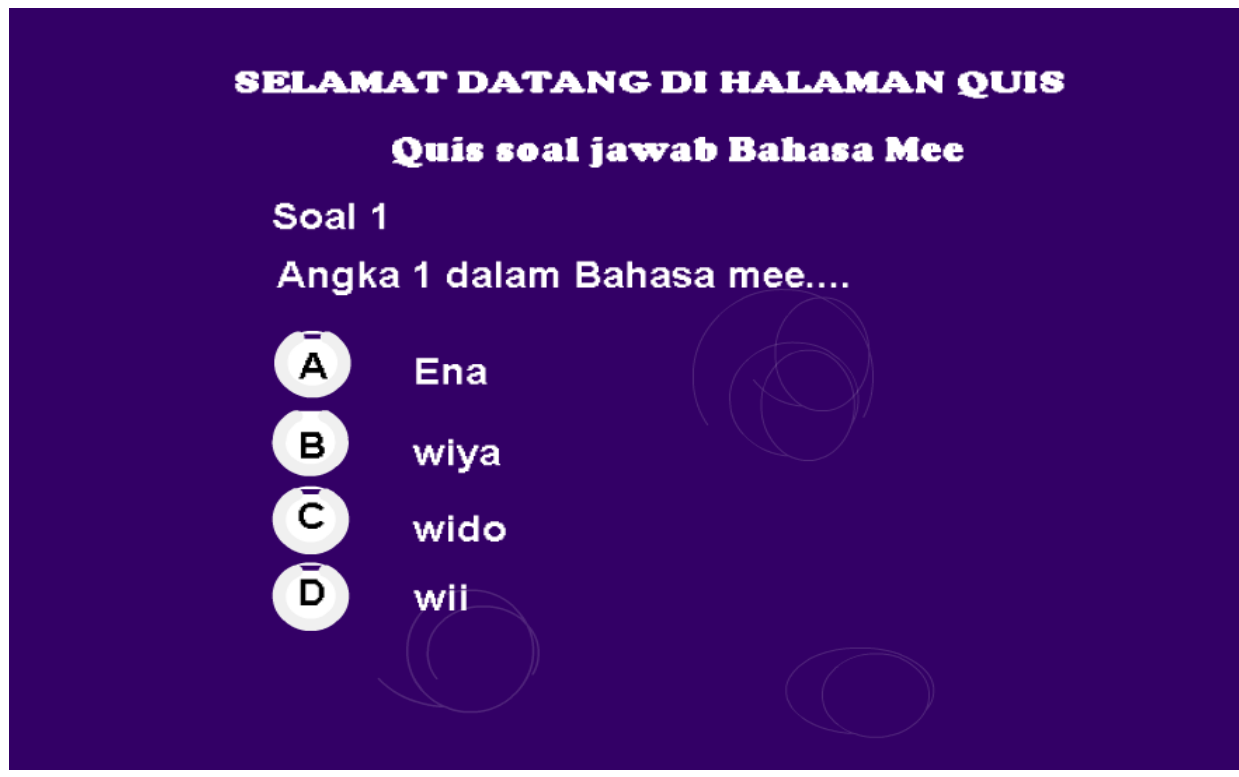

Gambar 12. Halaman Kuis

\subsection{Validasi}

Adapun tahapan validasi dilakukan setelah aplikasi media pembelajaran selesai dikerjakan yaitu dari asil penilaian ahli materi dan ahli media adalah sebagai berikut:

a. Validasi Ahli Materi yaitu oleh Ibu Erny Dikta Sumantik S.Pd., M. Li dengan hasil analisis data validasi adalah $90 \%$ maka dapat dikategorikan "sangat baik" dari tabel kelayakan yang digunakan.

b. Validasi Ahli Media oleh Bapak Axelon Renyaan S.SI., M.T dengan analisis data validasi adalah $85 \%$ maka dapat dikategorikan "sangat Baik" dari tabel kelayakan yang digunakan.

\section{KESIMPULAN}

Dari hasil pembahasan penelitian mengenai media pembelajaran bahasa mee berbasis mutimedia interaktif maka dapat disimpulkan bahwa proses rancang bangun media pembelajaran Bahasa Mee berbasis multimedia interaktif telah dikerjakan dengan baik sesuai dengan kerangka berpikir dan metode pengembangan sistem yang dipakai serta nilai interpretasi dari ahli materi dan ahli media. Harapan selanjutnya adalah pengembangan di tingkat lanjut dan menengah dalam pengolahan media pembelajaran bahasa mee baik pada sistem bilangan dan aspek bahasa Mee.

\section{UCAPAN TERIMA KASIH}

Kami panjatkan terimakasih kepada bapa Pendeta Yulius Bunai Sekeluarga dan Dinas Pendidikan dan Kebudayaan Kabupaten Paniai Provinsi Papua sehingga proses penelitian ini dapat terselesaikan dengan baik. 


\section{DAFTAR PUSTAKA}

[1] H.Takimai,"Kamus praktis bahasa mee - indonesia", Papua:aseni Emas Nusantara., 2015, ISBN: 978-602-70424-4-5.

[2] M. N. N. Sitokdana, "Traditional Number System Ok And Mek Tribes In Papua Island," no. 1, 2018.

[3] H.E.Manurung et al.,"Perancangan Modul Pembelajaran Numeralia Dalam Bahasa Biak Berasis Interactive Multimedia Learning", pp. 135-143, 2019.

[4] Sugiyono, "Metode Penelitian Kombinasi (Mixed Methods)", Bandung:Alf., 2010, doi: 10.1016/S0969-4765(04)00066-9.

[5] Sugiyono, "Metode Penelitian Kuantitatif,Kualitatif dan R\&D", Bandung: Alf., 2016, ISBN:9798433-64-0.

[6] P. A. Nanda, "Simulasi Visualisasi Teknik Gerakan Yoga Dengan Metode Pengembangan Multimedia Luther-Sutopo Berbasis Mobile," JURIKOM (Jurnal Ris. Komputer), vol. 7, no. 2, p. 207, 2020, doi: 10.30865/jurikom.v7i2.1944.

[7] Angraini W, Prihantoro C, Amin M, Yanuarti R. Penerapan Media Audio Visual Dalam Peningkatan Angka Pemberian Air Susu Ibu (Asi) Eksklusif Di Desa Kurotidur Kecamatan Argamakmur Kabupaten Bengkulu Utara. Jurnal Pengabdian Masyarakat Bumi Raflesia. 2019 May 5;2(1).

[8] N. Annisa, A. H. Saragih, and R. Mursid, "Pengembangan Media Pembelajaran Interaktif Pada Mata Pelajaran Bahasa Inggris," J. Teknol. Inf. Komun. Dalam Pendidik., vol. 5, no. 2, pp. 210 221, 2019, doi: 10.24114/jtikp.v5i2.12599.

[9] R. H. Wirasasmita and Y. K. Putra, "Pengembangan Media Pembelajaran Video Tutorial Interaktif menggunakan Aplikasi Camtasia Studio dan Macromedia Flash," EDUMATIC J. Pendidik. Inform., vol. 1, no. 2, p. 35, 2018, doi: 10.29408/edumatic.v1i2.944.

[10] R. Basyir, "Rancang Bangun Aplikasi Android Media Pembelajaran Kosa Kata Bahasa Arab Bergambar Dengan Menggunakan Model Pendekatan Addie,” Edutic - Sci. J. Informatics Educ., vol. 3, no. 1, 2017, doi: 10.21107/edutic.v3i1.2599.

[11] E. I. Apriliani, K. Y. Purwanti, and R. W. Riani, "Peningkatan Kesantunan Bahasa Anak Usia Dini melalui Media Pembelajaran Interaktif Budaya Jawa,” J. Obs. J. Pendidik. Anak Usia Dini, vol. 5, no. 1, p. 150, 2020, doi: 10.31004/obsesi.v5i1.319.

[12] S. M. P. Mts, "Pengembangan media pembelajaran interaktif," Pengemb. media pembelajaran interaktif powerpoint Berbas. inkuiri terbimbing, vol. XIII, no. 2, pp. 136-145, 2019.

[13] M. I. A. Ukkas, D. Cahyadi, and N. Nurabdiansyah, "Media Pembelajaran Bahasa Inggris Interaktif Pictionary," TANRA J. Desain Komun. Vis. Fak. Seni dan Desain Univ. Negeri Makassar, vol. 6, no. 1, p. 1, 2019, doi: 10.26858/tanra.v6i1.9949.

[14] R. Komarudin and R. R. Noor, "Analisis Perancangan Media Pembelajaran Animasi Interaktif Mengenal Bahasa Jepang,” J. Pilar Nusa Mandiri, vol. 13, no. 1, pp. 12-20, 2017, [Online]. Available: http://ejournal.nusamandiri.ac.id/ejurnal/index.php/pilar/article/view/330.

[15] S. Syahroni and M. Nurfitriyanti, "Pengembangan Media Pembelajaran Interaktif Berbasis Komputer dalam Pembelajaran Matematika, Materi Bilangan pada Kelas 3 SD," Form. J. Ilm. Pendidik. MIPA, vol. 7, no. 3, pp. 262-271, 2018, doi: 10.30998/formatif.v7i3.2237.

[16] M. Huda and N. Taufik, "Media Pembelajaran Interaktif Berbasis Adobe Flash Untuk Meningkatkan Pemerolehan Kosa Kata Bahasa Arab Siswa Masa Kini," no. 2002, pp. 43-55, 2020 . 